HALAC

\title{
A Agroecologia Ontem, Hoje e Amanhã em Terras Tupiniquins: Conceito, Contexto e Perspectivas
}

\author{
Kárita de Jesus Boaventura ${ }^{1}$; Wesley Fonseca Vaz² Éder Dasdoriano Porfírio Júnior ${ }^{3}$; Carlos de \\ Melo e Silva Neto ${ }^{4}$; Murilo Mendonça Oliveira de Souza ${ }^{5}$
}

\section{RESUMO}

A agroecologia parte da ideia que é possível o desenvolvimento de uma agricultura sustentável. Por isso, o presente trabalho tem como objetivo analisar a agroecologia enquanto alternativa para mitigar a degradação ambiental que a agricultura convencional tem causado. Trata-se de uma revisão bibliográfica baseada na literatura especializada através de consulta a livros, artigos científicos e leis que corroboraram com as informações e análises aqui apresentadas. O trabalho está estruturado da seguinte forma: 1. Trabalha-se o conceito de agroecologia segundo autores da literatura acadêmica; 2. É feito uma contextualização histórica do surgimento da agroecologia no mundo e, posteriormente, no Brasil; 3. É vista a situação da agroecologia atualmente, com ênfase para os problemas que a mesma tem enfrentado; 4. É analisada a inserção dos agrotóxicos na agricultura convencional; 5. E por fim, é apresentada como se deu a estruturação legal da agroecologia no Brasil. Constatou-se que a agricultura atual tem se estruturado pela elevada dependência em relação aos insumos químicos, mecanização intensiva e uso insustentável dos recursos naturais, por isso é necessário que haja um diálogo dessas práticas com as ações da agroecologia.

Palavras-Chave: Terra; Agricultura Convencional; Degradação Ambiental; Mecanização; Legislação.

\footnotetext{
1 Doutoranda no Programa de Pós-graduação em Recursos Naturais do Cerrado pela Universidade Estadual de Goiás.Professor na rede estadual de ensino karitaboaventura@hotmail.com

2 Doutorado em andamento em Recursos Naturais do Cerrado pela Universidade Estadual de Goiás Professor no Instituto Federal de Educação Ciencia e Tecnologia de Mato Grosso wesfonseca@gmail.com

3 Doutorado em andamento em Recursos Naturais do Cerrado pela Universidade Estadual de Goiás Professor no Instituto Brasileiro do Meio Ambiente e dos Recursos Naturais Renováveis ederdpjunior@gmail.com

4 Doutorado em Agronomia pela Universidade Federal de Goiás Professor no Instituto Federal de Educação, Ciência e Tecnologia de Goiás carloskoa@gmail.com

${ }^{5}$ Doutorado em Geografia pela Universidade Federal de Uberlândia Professor na murilosouza@hotmail.com
} 


\section{INTRODUÇÃO}

A vida no planeta tem sofrido constante ameaça de extinção, sendo que essa tem se estendido não só à flora e a fauna, mas também a qualquer ser que o habita, inclusive nós, seres humanos. As razões para esse "apocalipse" em que talvez resistam os prédios, as estradas, as indústrias, os carros, mas em que a vida perece, advém principalmente das ações humanas em prol justamente de se ter mais prédios, estradas, indústrias, carros, etc.

A ação antrópica sobre a Terra tem se intensificado com o passar dos séculos devido a necessidade do ser humano em adaptar o meio em que vive às suas demandas. Essas são determinadas pela constante mudança no estilo de vida das populações que passa a precisar explorar cada vez mais os recursos naturais.

Nos tempos mais remotos, ainda no Neolítico, quando o homem deixa de ser nômade e passa a ser sedentário, começando a cultivar vegetais e criando animais para sua subsistência, já pode ser observada a pegada ecológica se expandindo e deixando rastros. Trilhas que com o passar do tempo vão ficando tão profundas que, dificilmente podem ser apagadas. ${ }^{6}$

Quando se pensa nessas marcas, ou, porque não, cicatrizes impostas ao planeta pelo homem, pode-se evidenciar diversos fatores que atualmente tem dificultado a vida na Terra, como poluição, desmatamento, problemas climáticos, falta de alimentos, falta de água, dentre inúmeros outros. Em meio a tantos problemas, o que mais se indaga é "O que é possível fazer a respeito?" Refletindo sobre isso, as respostas são óbvias, vem rápido e são bem pragmáticas: "poluir menos, desmatar menos, economizar água".

A grande questão é que para essas "soluções óbvias" entrarem em prática, o homem enquanto ser social, em uma sociedade capitalista, tem que ceder, às vezes, indo contra suas ideologias e perspectivas de futuro, e isso para que haja um futuro. No entanto, a percepção que se tem, observando o avanço da degradação do planeta,

\footnotetext{
${ }^{6}$ Valdir Lamim-Guedes. Pegada ecológica: consumo de recursos naturais e meio ambiente. Educação Ambiental e Ação. 38 (dez.-fev./2011-2012), http://www.revistae.org/artigo.php?idartigo=1168
} 
é que mesmo já sofrendo bastante com todo o caos de perturbações que sua interferência tem causado, o homem, apesar de reconhecer o problema, não quer ceder, se para isso tiver que arcar com algum tipo de prejuízo. A ganância humana é tão insana que para ter mais, corre-se o risco de deixar de existir.

Todavia, em meio ao caos, há os que tentam resistir, os que ainda acreditam na preservação, na mitigação da degradação, no planeta enquanto "casa". E, em meio a essa resistência surgem conceitos, ideias, ciências. Dessas últimas, nesse texto irá ser ressaltada a agroecologia procurando analisar as diversas visões sobre o seu conceito, contexto histórico de nascimento no Brasil, sua atual situação em território nacional e como anda o embate dessa nova ciência com a agricultura convencional.

A partir do exposto, tendo como metodologia uma pesquisa bibliográfica que primou pela consulta de livros, artigos científicos e leis, que corroboraram com as informações e análises apresentadas, o presente trabalho tem como objetivo analisar a agroecologia enquanto alternativa para mitigar a degradação ambiental que a agricultura convencional tem causado. Faz-se aqui uma análise de pontos já abordados na literatura acadêmica contrapondo diferentes vertentes a partir de diversos autores e leis, para tanto reflete-se sobre o conceito de agroecologia, contextualiza-se o surgimento da agroecologia no mundo e no Brasil. Também é pontuada a situação da agroecologia atualmente, abordando a questão da inserção dos agrotóxicos na agricultura convencional, e ainda é analisada como se deu a estruturação legal da agroecologia no Brasil. Com a constatação de que a agricultura atual tem se estruturado pela elevada dependência em relação aos insumos químicos, mecanização intensiva e uso insustentável dos recursos naturais, salienta-se a necessidade de que haja um diálogo dessas práticas com as ações da agroecologia para que essa última tenha real visibilidade e possa ser praticada mesmo ante a economia de mercado atual.

\section{O QUE É A AGROECOLOGIA?}

A agroecologia, a princípio, parte do desenvolvimento rural desde que esse seja menos agressivo ao meio. É utopia pensar em coexistir com o meio sem deixar 
marcas, no entanto, a agroecologia procura minimizar essas marcas, de forma que haja o menor prejuízo possível à terra. Todavia, antes de se chegar a falar em agroecologia, outros conceitos foram trabalhados. Nesse âmbito, a literatura menciona, por exemplo, o "desenvolvimento rural sustentável" que, segundo Azevedo e Netto ${ }^{7}$, é entendido como forma de melhorar a vida da população do campo a partir da participação camponesa para potencializar os seus recursos.

Seguindo essa linha de raciocínio, ainda segundo Azevedo e $\mathrm{Netto}^{8}$, a agroecologia hoje faz a transição entre a agricultura convencional e a agricultura sustentável. O diferencial seria o reconhecimento da importância do saber popular dos agricultores, evidenciando o quesito social, cultural e, não só o econômico.

Partindo do exposto, no contexto do desenvolvimento sustentável emerge a agroecologia enquanto disciplina, ou até uma ciência, de caráter multidisciplinar, que dá importância ao que o agricultor tem a dizer. O que se pretende nessa, é valorar a vivência e os ganhos que vieram a partir de anos de "erros e acertos" com as tentativas desses indivíduos. Afinal de contas, um pescador que nunca frequentou uma escola tem muito a dizer e ensinar de seu ofício, mesmo não sabendo conceituar o que é uma ciência. Então, a questão é porque não ouvir e valorar essa experiência que surgiu a partir de práticas e vivências, que tem como maior prova de autenticidade e veracidade a perpetuação de uma profissão, ou de comunidades inteiras que ainda vivem da pesca? Assim sendo, numa tentativa de conceituar a agroecologia levando o conhecimento do agricultor em consideração, temos:

Em anos mais recentes, a referência à Agroecologia, que se constitui em mais uma expressão sócio-política do processo de ecologização, tem sido bastante positiva, pois nos faz lembrar de estilos de agricultura menos agressivos ao meio ambiente, que promovem a inclusão social e proporcionam melhores condições econômicas aos agricultores. Nesse sentido, são comuns as interpretações que vinculam a Agroecologia com "uma vida mais saudável"; "uma produção agrícola dentro de uma lógica em que a natureza mostra o caminho"; "uma agricultura socialmente justa"; "o ato de trabalhar dentro do meio ambiente, preservando-o"; "o equilíbrio entre nutrientes, solo, planta, água e animais"; "um novo equilíbrio nas relações homem e natureza"; uma

\footnotetext{
7 Letícia Fátima de Azevedo and Tatiane Almeida Netto. Agroecologia: o caminho para o desenvolvimento rural sustentável no processo de extensão rural. In Revista Eletrônica em Gestão, Educação e Tecnologia Ambiental, 19,3 (set.-dez. 2015), 639-645, https://periodicos. ufsm.br/reget/ article / view /17031

8 Letícia Fátima de Azevedo and Tatiane Almeida Netto. Agroecologia: o caminho para o desenvolvimento rural sustentável no processo de extensão rural. In Revista Eletrônica em Gestão, Educação e Tecnologia Ambiental, 19,3 (set.-dez. 2015), 639-645, https://periodicos. ufsm.br/reget/ article / view /17031
} 
agricultura sem destruição do meio ambiente"; "uma agricultura que não exclui ninguém"; entre outras. Assim, o uso do termo Agroecologia nos tem trazido a ideia e a expectativa de uma nova agricultura capaz de fazer bem ao homem e ao meio ambiente. ${ }^{9}$

Contudo, apesar de até agora parecer que não se está ressaltando nada de "fantástico" e de que tudo é muito plausível, a agroecologia tem enfrentado problemas. Começa-se a falar em agroecologia em 1970, mas seu ideal é tão antigo quanto o da própria agricultura. Sua estratégia, segundo Azevedo e Netto ${ }^{10}$, é transformar uma abordagem disciplinar em temática "por meio da mudança sobre o uso de insumos e/ou o redesenho de agroecossistema, buscando formatos tecnológicos que beneficiam a inclusão social, apoiando a heterogeneidade de estratégias de uso e manejo dos recursos naturais". No entanto, ao falar de agroecologia enquanto ciência, ou disciplina, há sobressaltos, principalmente quando observado que se comparada à agricultura convencional, em um processo de transição, essa última teria que ser muito modificada, e o objetivo do dono da terra não seria a mais-valia como foco principal. Outro ponto de controvérsia é a valoração do conhecimento do agricultor, pontuado em muitos momentos enquanto não científico, mas superestimado dentro da agroecologia.

Portanto, é preciso reconhecer que entre os agricultores e suas famílias existe um saber, um conjunto de conhecimentos que, embora não sendo de natureza científica, é tão importante quanto os nossos saberes. Disso resulta que nossa ação - ao mesmo tempo em que deve ser respeitosa para com os saberes dos demais - deve ser capaz de contribuir para a integração destes diferentes saberes, buscando a construção social de conhecimentos adequados para o desenvolvimento dos potenciais agrícolas de cada agroecossistema e dos potenciais de desenvolvimento sustentáveis presentes em cada comunidade. ${ }^{11}$

Avaliando um possível processo de transição da agricultura convencional para a agroecologia, tem-se que ter claro que os agroecossistemas são abertos e podem receber insumos externos, gerando produtos que podem sair de seus limites. Sendo assim, em um sistema agroecológico há a abertura para a miscigenação dos conhecimentos tradicionais com as novas tecnologias:

\footnotetext{
${ }^{9}$ Francisco Roberto Caporal and José Antônio Costabeber. "Agroecologia: alguns conceitos e princípios". (Brasília: MDA/SAF/DATER-IICA, 2004: 06), http://www.fca.unesp. br/Home /Extensao / G rupoTimbo/ AgroecologiaConceitoseprincipios.pdf

${ }^{10}$ Letícia Fátima de Azevedo and Tatiane Almeida Netto. "Agroecologia: o caminho para o desenvolvimento rural sustentável no processo de extensão rural”, p. 643.

${ }_{11}$ Francisco Roberto Caporal and José Antônio Costabeber. "Agroecologia e Desenvolvimento Rural Sustentável: perspectivas para uma Nova Extensão Rural". Agroecologia e Desenvolvimento Rural Sustentável. Porto Alegre, 1:1, (jan./mar.,2000), 32, http: // www . projetovidanocampo.com.br /agroecologia/ agroecologia_e_desese nvolvimento.pdf
} 
Os pesquisadores que percebem o agroecossistema como o resultado da coevolução entre os processos sociais e naturais entendem que os processos ecológicos mencionados correm paralelamente e são interdependentes da dinâmica socioeconômica. Da mesma forma o desenvolvimento ou adoção de sistemas agrícolas ou tecnologias são resultado da interação entre os agricultores e seus conhecimentos e o ambiente biofísico e socioeconômico. ${ }^{12}$

Refletindo sobre o mencionado, Carmo $^{13}$ discorre que a abordagem agroecológica, de certa forma, incentiva os pesquisadores a estudar o manejo dos agricultores, isso a fim de desenvolver uma dependência mínima dos insumos químicos. O objetivo seria restabelecer o equilíbrio com o meio produzindo em quantidade e com qualidade, em um processo que, conscientemente, não seria breve. Sobre isso, Primavesi ${ }^{14}$ afirma:

A ecologia se refere ao sistema natural de cada local, envolvendo o solo, o clima, os seres vivos, bem como as inter-relações entre esses três componentes. Trabalhar ecologicamente significa manejar os recursos naturais respeitando a teia da vida. Sempre que os manejos agrícolas são realizados conforme as características locais do ambiente, alterando-as o mínimo possível, o potencial natural dos solos é aproveitado. Por essa razão, a Agroecologia depende muito da sabedoria de cada agricultor desenvolvida a partir de suas experiências e observações locais.

Corroborando com a autora acima, Caporal e Costabeber ${ }^{15}$ enfatizam que um dos eixos principais da agroecologia é a necessidade de produzir alimentos em quantidade e qualidade para toda a sociedade. Os autores mencionam ainda que, para tanto, a agroecologia absorve diversas disciplinas tendo uma ampla área de análise por possuir uma base que enfatiza a relação entre o sistema social e o ecológico. Por isso,

(...) na Agroecologia, é central o conceito de transição agroecológica, entendida como um processo gradual e multilinear de mudança, que ocorre através do tempo, nas formas de manejo dos agroecossistemas, que, na agricultura, tem como meta a passagem de um modelo agroquímico de produção (que pode ser mais ou menos intensivo no uso de inputs industriais) a estilos de agriculturas que incorporem princípios e tecnologias de base ecológica. Essa ideia de mudança se refere a um processo de evolução contínua e crescente no tempo, porém sem ter um momento final determinado. Entretanto, por se tratar de um processo social, isto é, por depender da intervenção humana, a transição

\footnotetext{
${ }^{12}$ Miguel Altieri. Agroecologia: bases científicas para uma agricultura sustentável (São Paulo: Expressão Popular, 2012), 202.

${ }_{13}$ Maristela Simões do Carmo. Agroecologia: Novos caminhos para a agricultura familiar. Revista Tecnologia \& Inovação Agropecuária, 1 (2008), 28-39, http://www.apta.sp.gov.b r/Publicacoes/ T\&IA2/ T \&l Av1 n2/ Artigo Agroecologia Novos Caminhos 3.pdf

${ }^{14}$ Ana Maria Primavesi. Agroecologia e manejo do solo. Agriculturas 5,3 (Setembro 2008), http:// aspta. org. br/wpcontent/uploads/2014/10/Artigo-1-Agroecologia-e-manejo-do-solo .pdf

${ }^{15}$ Francisco Roberto Caporal and José Antônio Costabeber. "Agroecologia: alguns conceitos e princípios".
} 
agroecológica implica não somente na busca de uma maior racionalização econômico-produtiva, com base nas especificidades biofísicas de cada agroecossistema, mas também numa mudança nas atitudes e valores dos atores sociais em relação ao manejo e conservação dos recursos naturais. ${ }^{16}$

Ainda segundo Caporal e Costabeber ${ }^{17}$, a agroecologia tem um viés de intervenção inovador e multidisciplinar. Esse viés tem sido construído a partir de uma crise no modelo tecnológico de organização e produção da agricultura. Esta última tem se manifestado na vida humana. Por isso, para vencer essa crise é preciso produzir novos conhecimentos, e esses devem ser aliados ao progresso científico e tecnológico, desde que adaptados à realidade socioeconômica e cultural das populações rurais. Nesse parâmetro, a agroecologia tem subsídios importantes caracterizando-se "como um movimento sociopolítico de fortalecimento do agricultor em busca de sua identidade e raízes culturais e, principalmente, de sua autonomia, poder de decisão e participação ativa no processo produtivo, favorecendo o local como foco de ação."18

\section{QUANDO E COMO A AGROECOLOGIA SURGIU?}

Quando se pensa na relação do homem com a terra e sua necessidade de subsistência fica evidente que a agricultura sempre teve um papel de destaque. Nos primórdios, quando o homem era nômade, caçador e coletor sua subsistência era menor, sua natalidade era menor, seu nível civilizacional (segundo padrões mais contemporâneos) era menor. Mas, quando se tornou sedentário e começou a cultivar seu alimento, há uma transformação em sua vida, ele passou a se nutrir melhor, sua taxa de natalidade aumentou, sua taxa de mortalidade diminuiu, ele passou a ser mais civilizado. Isso evidencia que o trato e manejo com a terra está intimamente ligado com uma pretensa qualidade de vida que o ser humano almeja, no entanto, essa qualidade de vida humana, como já mencionado, tem trazido consequências ao planeta. E, a literatura tem atestado isso: "Desde os primórdios da civilização, das primeiras Revoluções Agrícolas até as duas Revoluções Agrícolas dos tempos

\footnotetext{
${ }^{16}$ Francisco Roberto Caporal and José Antônio Costabeber. "Agroecologia: alguns conceitos e princípios”, 12. Francisco Roberto Caporal and José Antônio Costabeber. "Agroecologia: alguns conceitos e princípios".

18 Elaine de Azevedo and Maria Cecília Focesi Pelicione. Promoção da saúde, sustentabilidade e agroecologia: uma discussão intersetorial. Saúde Soc., 20,3 (2011), 720 http://www.scielo.br /scielo . php? script= sci arttext\&pid=S0104$\underline{12902011000300016}$
} 
modernos, ao longo de 10 mil anos, a agricultura sempre foi a principal forma de relação do ser humano com a natureza, apresentando no tempo e no espaço diferentes intensidades de impacto no meio ambiente." 19

Ao analisar a história da humanidade, é observado que essa relação do homem com a terra tem tido diferentes intensidades, tudo dependendo sempre do interesse e da importância que é imputada à terra. Quando se volta no tempo percebe-se que, na verdade, a terra sempre esteve no rol de anseios e cobiças humanas. No Paleolítico a terra era provedora, haja vista que o homem, enquanto caçador e coletor, tinha que se contentar com o que ela podia oferecer, nesse período havia pegadas ecológicas humanas, no entanto, essas eram bem "rasas". Já no Neolítico, quando começa a agricultura, há um empoderamento do homem sobre a terra, pois esse percebe que ele tem o poder de a manejar e a fazer produzir o que fosse de sua necessidade. $\mathrm{Na}$ antiguidade, terra significava poder, e o rei, ou o nobre que possuía mais terra também possuía mais poder. Na idade média, quando há a ruralização das cidades e as pessoas saem dessas e retornam ao campo, a terra volta a ter o status de subsistência, mas também é uma forma de exclusão social onde quem a tem é nobre, ou senhor feudal, ou suserano e, quem não a tem é servo, ou vassalo, tendo que trabalhar para o primeiro a fim de ter acesso a mesma. Na modernidade, com a expansão marítima e comercial, terra volta a ser sinônimo de riqueza e poder, e isso é evidenciado quando a Europa passa a concorrer entre si em uma disputa desenfreada para ver qual Estado "descobre", ou conquista mais terras e, obviamente, se apropria de suas riquezas naturais e seus habitantes. Por fim, na contemporaneidade, terra é capital, seja como forma de acúmulo para valorização e especulação, seja na forma de exploração ou prospecção de recursos naturais, seja na forma de produção e consumo.

Historicamente, pensando na modernidade e contemporaneidade, Bianchini e Medaets $(2013)^{20}$ citam que a partir do século XVI, a Europa sedia o que ficou conhecido como "Primeira Revolução Agrícola". Nessa, a lavoura é integrada à pecuária, e surgem novos equipamentos que são aliados ao processo de produção, se

\footnotetext{
${ }^{19}$ Valter Bianchini and Jean Pierre Passos Medaets. Da revolução verde à agroecologia: Plano Brasil Agroecológico. http://www.mda.gov.br/portalmda /sites/default/files/user arquivos $195 /$ Brasil\% 20 Agro ecol \%C3\%B3gico\%2027$1113 \% 20$ Artigo \% 20Bianchini\%20e\%20Jean\%20Pierre.pdf

${ }^{20}$ Valter Bianchini and Jean Pierre Passos Medaets. "Da revolução verde à agroecologia: Plano Brasil Agroecológico".
} 
modernizando com o passar do tempo. Isso fez com que houvesse um crescimento da produção em quase todo o mundo. Depois, quando houve a transição da agricultura tradicional para a agricultura intensiva em insumos, abriu-se espaço para o que foi chamado de "Segunda Revolução Agrícola". Essa última foi caracterizada por uma crescente dependência da agricultura à indústria que acabou ditando normas à primeira, como por exemplo, o que deveria ser plantado, quando e como, tudo baseado na necessidade do mercado de consumo, que no fim, funcionava como o "coração" de toda essa operação. Quando a agricultura passou a depender da indústria, evidenciou-se uma forte homogeneização da produção e, concomitantemente, mais danos ambientais ao planeta. Ainda segundo Bianchini e Medaets $^{21}$; Caporal e Costabeber ${ }^{22}$, a Segunda Revolução Agrícola chega ao seu ápice no final do século XIX, com o advento da Revolução Industrial e, a sua consequente propagação.

Arcanjo $^{23}$, Camargo ${ }^{24}$ e Tauil et al. $^{25}$ discorrem que, um pouco mais tarde, na luta contra a malária nos seringais da Amazônia brasileira, ganha destaque o extermínio dos vetores, havendo ênfase aos inseticidas utilizados. Durante a Segunda Guerra Mundial, em 1939, um químico suíço chamado Paul Muller criou o inseticida DDT (Dicloro-Difenil-Tricloroetano) que além de ser capaz de matar os vetores da malária era de baixo custo. Durante a Segunda Guerra Mundial (1939-1945), as "doenças do Brasil", como eram chamadas a doença de Chagas, a malária e a ancilostomose, foram motivo de grande preocupação sendo vistas como ameaças principalmente porque o Brasil era um dos mais importantes fornecedores de matéria-prima aos países em guerra. E, enquanto o resto do mundo estava em guerra pelos mais variados motivos, aqui a "guerra" foi travada contra os vetores das doenças, os doentes eram tratados principalmente com antibióticos e, os vetores eram

\footnotetext{
${ }^{21}$ Valter Bianchini and Jean Pierre Passos Medaets. "Da revolução verde à agroecologia: Plano Brasil Agroecológico".

${ }^{22}$ Francisco Roberto Caporal and José Antônio Costabeber. "Agroecologia e Desenvolvimento Rural Sustentável: perspectivas para uma Nova Extensão Rural”. Agroecologia e Desenvolvimento Rural Sustentável.

${ }^{23}$ Ana Ruth Lima Arcanjo. Estudo da aplicabilidade dos testes imunocromatográficos como diagnóstico da malária na atenção básica de saúde no município de Manaus. (Dissertação de Mestrado, Universidade Estadual do Amazonas, 2004), http: //www. pos. uea. edu .br/data/area/dissertacao/download/2-1.pdf.

24 Erney Plessmann Camargo. Malária, maleita, paludismo. Revista Ciência e Cultura. 55,1 (Jan.-Mar. 2003), http://cienciaecultura.bvs.br/ scielo. php? pid=s0009-67 252003000100021 \& script = sci arttext

${ }_{25}$ Pedro Tauil, et al. A malária no Brasil. Caderno de Saúde Pública 1,1 (Jan.-Mar 1985) http://www.scielo.br/scielo.php?script=sci 131arttext \&pid = S0102-311X 1985000100009
} 
combatidos com inseticidas. Quanto a isso, é necessário salientar que houve crítica de ambientalistas que argumentavam que o uso do DDT, sem os devidos cuidados, matava o vetor da malária e também parte da flora e fauna circunvizinha ao borrifo, causando assim danos ambientais imensuráveis.

Nesse limiar há a inserção da química agrícola na lógica de mercado trabalhada na época, ou seja, "produzir mais em menos tempo". Essa, por sua vez, é apoiada por grandes potências mundiais como os Estados Unidos, praticamente toda a Europa e pelos países em desenvolvimento, dando início a um outro movimento conhecido dessa vez como "Revolução Verde".

Assis $^{26}$ cita que, com o pretexto de "solucionar o problema da fome mundial", a Revolução Verde obteve aumentos extraordinários em produtividade, tanto que, "entre 1950 e 1984, a produção alimentar dobrou e a disponibilidade de alimento por habitante aumentou 40\%". Lógico que isso não quer dizer que todo habitante tinha realmente acesso a esses alimentos.

Quando se traz a questão para âmbito nacional, o que se observa é que a pegada ecológica humana tem uma marca maior a partir da colonização europeia, não está se afirmando aqui que o nativo também não deixava sua pegada na terra, nem tão pouco minimizando essa, no entanto, não é objetivo desse trabalho entrar nessa questão. O fato é que questões históricas relacionadas ao desmatamento e má conservação do solo são evidenciadas depois da chegada dos europeus em terras tupiniquins. Todavia, dentre os movimentos e revoluções citados até agora, é a Revolução Verde, entre os anos de 1960 e 1970, marcada pela mecanização da agricultura que, segundo a literatura, teve papel primordial nos problemas ecológicos enfrentados pelo Brasil atualmente. Não está se sugerindo que esses problemas tenham surgido somente com o advento da Revolução Verde, afinal é notória a devastação em território nacional em todo o processo de colonização. No entanto, o que se coloca é que esses problemas ganharam mais importância e passaram a ser

\footnotetext{
${ }^{26}$ Renato Linhares de Assis. Agroecologia: Visão Histórica e Perspectivas no Brasil. In Aquino, A. M. de; Assis, R. L. de. (Ed.). Agroecologia: princípios e técnicas para uma agricultura orgânica sustentável. (Brasília: Embrapa Informação Tecnológica; Seropédica: Embrapa Agrobiologia, 2005), 176 https://www. agencia. cnptia. em brapa .br /recursos/AgrobCap7ID-MWV9UkYXu0
} 
mais percebidos em toda a sua extensão a partir da Revolução Verde, como afirmado a seguir:

É nesse contexto que a pesquisa e o desenvolvimento dos modernos sistemas de produção foram orientados para a incorporação de pacotes tecnológicos, tidos como de aplicação universal, destinados a maximizar o rendimento dos cultivos em situações ecológicas profundamente distintas. Além disso, apesar do processo de modernização ter proporcionado à agricultura brasileira um grande dinamismo nos seus componentes estruturais, este teve um caráter excludente, aumentando a concentração de riquezas e disparidades regionais no País, além dos desequilíbrios ecológicos e comprometimento dos ganhos de produtividade. $^{27}$

Segundo $\mathrm{Carmo}^{28}$, no Brasil a Revolução Verde se deu por duas vertentes: "as inovações de natureza biológica elevando a produtividade da terra, e as inovações mecânicas para elevação da produtividade do trabalho". Contudo, isso divergia veementemente da real situação do país no momento, que dispunha apenas de mão de obra camponesa, e terras, concentradas, porém abundantes. Mas faltava capital e desenvolvimento nas pesquisas a fim de adaptar a modernização ao mercado interno de trabalho.

Nesse âmbito, evidenciaram-se os problemas pois, segundo Assis ${ }^{29}$, a mecanização da agricultura atendeu prioritariamente ao aumento da produtividade agrícola, não se atentando ao agricultor e ao ambiente como partes do processo, a consequência foi uma gama de problemas sociais e ambientais. Concomitante, "surgiram movimentos de agricultura alternativos ao modelo de produção atualmente predominante, baseados em princípios agroecológicos e caracterizados por diferentes correntes de pensamento". Então, da crise surgem concepções alternativas e, em meio a essas está a agroecologia: "Da percepção da crise do padrão moderno de agricultura emergiu a discussão sobre a necessidade de promover estilos alternativos de agricultura. Dentre um desses estilos está a agroecologia, cujos princípios e

\footnotetext{
${ }^{27}$ Renato Linhares de Assis. "Agroecologia: Visão Histórica e Perspectivas no Brasil”. In Aquino, A. M. de; Assis, R. L. de. (Ed.). Agroecologia: princípios e técnicas para uma agricultura orgânica sustentável, p. 176.

${ }^{28}$ Maristela Simões do Carmo. "Agroecologia: Novos caminhos para a agricultura familiar", p. 30.

${ }^{29}$ Renato Linhares de Assis. "Agroecologia: Visão Histórica e Perspectivas no Brasil”. In Aquino, A. M. de; Assis, R. L. de. (Ed.). Agroecologia: princípios e técnicas para uma agricultura orgânica sustentável, p. 175.
} 
métodos pretendem desenvolver uma agricultura que seja ambientalmente consistente, altamente produtiva e economicamente viável"30.

Todavia, sobre isso, Caporal e Costabeber ${ }^{31}$ dizem que há tempos, o ser humano tem tentado praticar uma agricultura menos agressiva ao meio, sendo essa capaz de fazer com que os recursos naturais sejam duráveis e resilientes ao próprio homem e ao tempo. No mundo todo há relatos destas agriculturas alternativas, mas com diferentes nomes, "orgânica, biológica, natural, ecológica, biodinâmica, permacultura, entre outras, cada uma delas seguindo determinadas filosofias, princípios, tecnologias, normas e regras, segundo as correntes a que estão aderidas". Entretanto, muitas vezes, essas agriculturas alternativas não conseguiram amenizar os problemas socioambientais que se tinha.

Em âmbito nacional, o que se observa é uma transição do que se chamou de "agricultura alternativa", para produção orgânica e, ao mesmo tempo, a aceitação, e até defesa, da agroecologia, inclusive como ciência. Bianchini e Medaets ${ }^{32}$ salientam que no início houve até uma confusão sobre o que é orgânico e, o que é agroecológico, mas que com uma melhor definição dos conceitos, correntes e filosofias, ficou implícito que a produção orgânica "se concentra na substituição de insumos químicos por aqueles de origem orgânica em uma produção voltada para mercados de nicho". Sendo que a agroecologia "procura estabelecer uma visão de mundo na qual os agroecossistemas sejam elementos balizadores de relações de produção e consumo sustentáveis".

Quanto a agroecologia, diante de tudo o que já foi dito, pode-se afirmar que ela é um modelo de produção agrícola preocupado em manter a produtividade do solo por mais tempo que o convencional. Para tanto, faz uso de instrumentos que mantem o solo fértil, podendo esse ser reutilizado em novos plantios. Nesse âmbito, a

\footnotetext{
${ }^{30}$ Alexander Ritter, Simone Elenice Castelan and Cassiana Grigoletto. Agroecologia, desenvolvimento sustentável e educação ambienta. Ministério da Educação Coordenação de Aperfeiçoamento de Pessoal de Nível Superior Programa Institucional de Bolsa de Iniciação à Docência, Sub-projeto: Agroecologia e desenvolvimento rural sustentável: Rio Grande do Sul, (2003): 2, http://www.sertao.ifrs.edu.br/ site/midias /arquivos/2013311105741464 artigo agroecologia, desenvolvimento sustentavel e educacao ambiental.pdf

${ }^{31}$ Francisco Roberto Caporal and José Antônio Costabeber. "Agroecologia: alguns conceitos e princípios”, p. 07.

32 Valter Bianchini and Jean Pierre Passos Medaets. "Da revolução verde à agroecologia: Plano Brasil Agroecológico", p. 07.
} 
agroecologia dispensa, ou evita, o uso de substâncias químicas valorizando o que é orgânico.

Pensando nessas substâncias químicas, segundo o Instituto Brasileiro do Meio Ambiente e dos Recursos Naturais (IBAMA, 2018) ${ }^{33}$, o Brasil é, desde 2008, um dos maiores consumidores e produtores de agrotóxicos do mundo. Em 2013, esse órgão afirma que foram produzidas mais de 400 toneladas de agrotóxicos e inseticidas no país e, por ano, cada brasileiro consome em média 5,2 litros de agrotóxicos através da ingestão de alimentos contaminados. A agroecologia salienta a notoriedade dos riscos que essas substâncias causam à saúde, além da degradação ao meio ambiente.

\section{AGROECOLOGIA HOJE}

Refletindo sobre a implantação desses modelos alternativos de agricultura e, principalmente, na agroecologia, tem-se que considerar as resistências e desafios que os mesmos sofrerão diante da presente realidade do agronegócio, isso tendo como objetivo uma maior sustentabilidade de recursos. Dentre esses desafios pode-se citar a falta de políticas públicas que favoreçam e regulamentem esses modelos, a resistência dos grandes e pequenos produtores, a imposição do mercado de se produzir mais e em menos tempo, dentre muitos outros fatores. Ritter et al. ${ }^{34}$ argumentam que a superação desses desafios depende do diálogo e "aprendizagem coletiva que se possam estabelecer entre diferentes setores da sociedade, assim como do reconhecimento de que a sustentabilidade encerra não apenas abstrações teóricas e perspectivas futuristas, mas também elementos práticos que devem ser adotados na vida cotidiana". E, ainda se tem que considerar que muitas consequências ambientais negativas causadas pela falta de consciência ambiental não são consideradas um problema pela opinião pública, "retardando o debate e a possível tomada de consciência da população, no sentido de apoiar a construção de propriedades de base agroecológica que visam o desenvolvimento sustentável, ou ainda de ações ambientais

\footnotetext{
${ }^{33}$ Instituto Brasileiro do Meio Ambiente e dos Recursos Naturais - IBAMA. "Químicos e Biológicos: Agrotóxicos" 2018. Disponível em http://www.ibama.gov.br/agrotoxicos. Acesso: Maio de 2018

${ }^{34}$ Alexander Ritter; Simone Elenice Castelan and Cassiana Grigotetto. "Agroecologia, desenvolvimento sustentável e educação ambiental", p. 15.
} 
mais ajustadas à noção de sustentabilidade". Sobre isso, Carmo ${ }^{35}$ chega a dizer que apesar da sociedade, teoricamente, concordar com meios mais sustentáveis de subsistência, isso ainda está no mundo das ideias, porque quando é pautado colocar a teoria em prática há resistência social se o que for mudado trouxer qualquer tipo de prejuízo financeiro.

$\operatorname{Assis}^{36}$ afirma que "o desenvolvimento rural sustentável depende de decisões políticas que procurem por meio do uso coordenado de instrumentos de política agrícola e ambiental, estimular a adoção, pelos agricultores, de modelos agroecológicos de produção". No entanto, para isso dar certo, é necessário que o sistema econômico reconheça os prejuízos ao ambiente provocados pela ação humana, e isso só será viável com a ação do Poder Público e a participação da sociedade na mitigação dos problemas causados pela agricultura convencional. Talvez uma forma de "tocar" a sociedade seja aproximar essas ideologias do desenvolvimento rural sustentável às pessoas mais interessadas e mais ligadas a essas questões, ou seja, a população rural. Todavia, antes é preciso conhecer essa realidade, para depois sugestionar mudanças: "A lógica familiar de produção ainda pode ser considerada o traço característico que une esse segmento social. Apreender sua lógica produtiva e reprodutiva significa relacionar o equilíbrio das necessidades da família com as possibilidades da unidade de produção, a terra e o trabalho, intimamente associados à gestão do negócio familiar". 37

Pensando mais precisamente na agroecologia, é considerado, segundo Assis ${ }^{38}$ "que as políticas voltadas para a difusão de modelos de produção devem ser construídas a partir da articulação das decisões locais e das demandas sociais". Dessa forma, no Brasil, por exemplo, seriam necessárias políticas que propiciassem uma maior e melhor distribuição de renda e meios de produção a população rural.

\footnotetext{
${ }^{35}$ Maristela Simões do Carmo. "Agroecologia: Novos caminhos para a agricultura familiar".

${ }^{36}$ Renato Linhares de Assis. "Agroecologia: Visão Histórica e Perspectivas no Brasil”. In Aquino, A. M. de; Assis, R. L. de. (Ed.). Agroecologia: princípios e técnicas para uma agricultura orgânica sustentável, p. 182.

${ }^{37}$ Maristela Simões do Carmo. "Agroecologia: Novos caminhos para a agricultura familiar", p. 31.

${ }^{38}$ Renato Linhares de Assis. "Agroecologia: Visão Histórica e Perspectivas no Brasil”. In Aquino, A. M. de; Assis, R. L. de. (Ed.). Agroecologia: princípios e técnicas para uma agricultura orgânica sustentável, p. 180.
} 
Bianchini e Medaets ${ }^{39}$ afirmam que para se chegar à agricultura agroecológica é necessário um monitoramento da agricultura, isso quanto a sua interferência ao meio ambiente, e também quanto os aspectos sociais e econômicos. Numa perspectiva de aliar o inevitável, ou seja, o manejo da terra, ao social, econômico e ambientalmente imputável, o ideal seria "combinar a eficácia econômica, com gastos ecológicos mínimos para a sociedade atual e futura, nos frutos do desenvolvimento de um território". Essa combinação comporia o objetivo da sustentabilidade dentro da agroecologia. Mas, para isso, como já dito, é necessário envolver a sociedade, principalmente a parcela mais intimamente ligada ao processo a priori, por isso, começar através da educação seria um bom ponto de partida:

\begin{abstract}
A inclusão e o incentivo à abordagem da agroecologia e dos sistemas orgânicos de produção nos diferentes níveis e modalidades de educação e ensino representam desafios a serem superados. Há necessidade de criação de políticas públicas que ampliem os processos de formação de professores e educadores; de orientação dos projetos pedagógicos dos cursos pelos princípios e diretrizes da agroecologia; de ampliação do acesso aos cursos, permitindo a inclusão das populações do campo e da floresta; de integração dos cursos de agroecologia com a educação do e no campo; e de iniciativas para reconhecimento dos cursos profissionalizantes em agroecologia pelos Conselhos Profissionais. ${ }^{40}$
\end{abstract}

Apesar da produção desenfreada de alimentos, sabe-se que a mesma é para atender, em grande parte, o mercado consumidor externo e, que bem pouco do que é produzido no Brasil permanece aqui. Isso tem sido percebido pelas camadas menos favorecidas que, nos últimos tempos, começaram a se unir sendo movidas pelos problemas socioambientais causados pelo agronegócio, e pela constante falta de alimento, ou acesso a esse, pela população mais carente. A questão é tão contraditória que Santos et al. ${ }^{41}$ chegam a mencionar que "o Brasil é um grande exportador de alimentos, porém milhares de pessoas passam fome no país". Observando essas questões, esse texto referência a agroecologia, enquanto uma forma de agricultura alternativa voltada para a sustentabilidade, que pode se apresentar enquanto opção à

\footnotetext{
${ }^{39}$ Valter Bianchini and Jean Pierre Passos Medaets. "Da revolução verde à agroecologia: Plano Brasil Agroecológico", p. 06.

40 Valter Bianchini and Jean Pierre Passos Medaets. "Da revolução verde à agroecologia: Plano Brasil Agroecológico", p. 13.

${ }^{41}$ Cristiane Francis dos Santos Tonezer and Anelise Graciele Rambo. Agroecologia e agricultura familiar: Um caminho

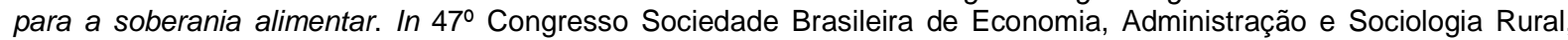
Porto Alegre, jul./2009: 8, http://www2. ufersa. edu. br/portal/ view/ up loads/setores/241/ Agroecologia \% 20 e \% 2 0Agricultura\%20Familiar\%20-\%20 Um\%20caminho \%20para\%20a\% 20soberania\% 20 Alimentar.pdf
} 
agricultura convencional como forma de melhorar a relação do homem com o meio e, ao mesmo tempo, dar ao ser humano condições de uma subsistência mais saudável.

Tendo o apontado em pauta e refletindo a literatura consultada, a agroecologia é pensada atualmente sob, pelo menos, duas vertentes: como movimento social e/ou como ciência. Enquanto movimento social, a agroecologia é vista como uma organização social que luta contra a agricultura tradicional dominadora vigente, isso se pensado no princípio preservacionista trazido pela agroecologia em contraposição à lógica capitalista de mercado vivida pela agricultura tradicional. Se pensada enquanto ciência, a agroecologia traz um conjunto de princípios e conceitos demonstráveis pela pesquisa empírica que podem mudar as práticas agrícolas se reavaliada a relação homem/natureza.

\section{AGRICULTURA CONVENCIONAL X AGROECOLOGIA: O CASO DOS AGROTÓXICOS}

\subsection{Um breve histórico sobre agrotóxicos}

Segundo Tourinho e Portela ${ }^{42}$, como já dito, a agroecologia é uma alternativa para uma prática agrícola menos agressiva ao meio ambiente. Sendo que essa propõe cultivos mais sustentáveis, relações de trabalho e comercialização mais justas em detrimento do uso indiscriminado de agrotóxicos.

Porém, Filho ${ }^{43}$ considera que, desde a antiguidade clássica, o ser humano utiliza substâncias químicas para controlar e eliminar problemas causados por ataques de pragas e doenças em plantações. Para tanto, foram utilizados metais como: cobre, enxofre, mercúrio, arsênico, selênio, chumbo e zinco além de substâncias orgânicas naturais como: piretrina, nicotina e rotenona, produtos estes derivados de flores e raízes.

No período que compreende o final do século XIX e início do século XX dá-se início ao desenvolvimento de inseticidas inorgânicos graças a transformação do cianato de amônio em ureia, essa síntese foi efetuada em 1828 pelo alemão Friedrich

\footnotetext{
${ }^{42}$ Raiza Tourinho and Graça Portela. Agroecologia é alternativa para cultivo agrícola mais sustentável (Rio de Janeiro: FIOCRUZ, 2016), https://portal.fiocruz.br/pt-br/ co ntent/agroecologia-e-alternativa-para-cultivo-agricola-mais-sustentavel 43 José Prado Alves Filho. Uso de agrotóxicos no Brasil: Controle social e interesses corporativos, Controle social e interesses corporativos. (São Paulo: Annablume: Fapesp, 2002), 23
} 
Wöhler. Contudo, a utilização em larga escala de inseticidas orgânicos se deu na década de 1940 com o objetivo de proteger os soldados, que combatiam em regiões tropicais e subtropicais da África e da Ásia, das pragas transmissoras da doença-dosono, malária, dentre outras. Todavia, é necessário salientar que além dos notórios malefícios à saúde, nesse contexto, quase desconhecidos, o uso desses inseticidas trouxe, já nessa época, problemas ambientais que só seriam percebidos e mensurados posteriormente. O fato é que, de acordo com Braibante e Zappe ${ }^{44}$, foi essa demanda militar a responsável por impulsionar as pesquisas de novos inseticidas resultando no desenvolvimento de vários agrotóxicos que são usados ainda hoje.

A descoberta da atividade inseticida do 1,1,1-tricloro-2,2-di(ם-clorofenil)etano, conhecido como DDT, em 1939, pelo entomologista suíço Paul Hermann Müller, é um importante marco tanto na indústria de agrotóxicos sintéticos bem como na ciência. Isso, tendo em vista que seu descobridor foi laureado com o Prêmio Nobel de Fisiologia ou Medicina em 1948 por sua descoberta da alta eficiência do DDT como um veneno de contato contra vários artrópodes.

Ainda sobre o DDT, D'amato et $\mathrm{al}^{45}$ citam que a sua descoberta revolucionou os conceitos de luta contra a malária, entre os anos de 1946 e 1970, por isso todos os programas de controle apoiavam quase que totalmente seu emprego. Ele também foi utilizado na Segunda Guerra Mundial para prevenção de tifo em soldados, que o utilizavam na pele para combater piolhos. Seu baixo preço e alta eficiência foram fatores determinantes para sua utilização na agricultura como pesticida, por cerca de 25 a 30 anos. Isso apesar de se ter consciência de que o seu uso ocasiona acúmulo no tecido adiposo de organismos vivos. Além da alta estabilidade, pois demora muitos anos para ser degradado na natureza. O uso incorreto e indiscriminado durante várias décadas trouxe consigo muitos problemas, dentre eles podemos citar a acumulação de resíduos tóxicos em alimentos, na água e no solo, intoxicação de produtores rurais, seleção de pragas resistentes, etc.

\footnotetext{
${ }^{44}$ Mara Elisa Fortes Braibante and Aline Zappe Janessa. A Química Dos Agrotóxicos. Química Nova Na Escola 34,1 (2012): 10-15.

${ }^{45}$ Claudio D’Amato, João P. M. Torres and Malm Olaf. DDT (Dicloro Difenil Tricloroetano): Toxicidade e Contaminação Ambiental - Uma Revisão. Química Nova 25,6 (2002): 995-1002.
} 
De acordo com o Ministério do Meio Ambiente (2017) a legislação vigente na forma da Lei Federal $\mathrm{n}^{0} 7.802 / 1989^{46}$, Decreto $\mathrm{n}^{\circ} 4.074 / 2002^{47}$ e Decreto $\mathrm{n}^{0} 5.981 / 2006^{48}$, os agrotóxicos são definidos como produtos e agentes de processos físicos, químicos ou biológicos, que são utilizados nos setores de produção, armazenamento e beneficiamento de produtos agrícolas, pastagens, proteção de florestas, nativas ou plantadas, e de outros ecossistemas e de ambientes urbanos, hídricos e industriais. Essa classe de compostos altera a composição da flora ou da fauna, a fim de preservá-las da ação danosa de seres vivos considerados nocivos. Os agrotóxicos podem ser divididos em duas categorias: Agrícolas e Não-agrícolas. Na primeira se enquadram aqueles destinados ao uso nos setores de produção, no armazenamento e beneficiamento de produtos agrícolas, nas pastagens e nas florestas plantadas, enquanto que na segunda temos aqueles destinados ao uso em ambientes urbanos e industriais, domiciliares, públicos ou coletivos, ao tratamento de água e ao uso em campanhas de saúde pública.

No entanto, é notório o prejuízo ambiental e à saúde, tanto de quem maneja quanto de quem se alimenta dos alimentos que tem contato com esses insumos. Bohner, Araújo e Nishijima ${ }^{49}$ afirmam que a "utilização destes insumos não só é responsável pela contaminação ambiental, mas também é a causa de muitos problemas de saúde pública, pois quando aplicados inadequadamente prejudicam o meio ambiente e a saúde dos trabalhadores rurais e dos consumidores". Salienta-se aqui que essa "aplicação inadequada" e em demasia ocorre corriqueiramente objetivando produzir sempre mais e em menos tempo.

4.2 - Considerações acerca da Agroecologia, Agricultura Orgânica e Agrotóxicos.

\footnotetext{
${ }^{46}$ Brasil. Lei № 7.802 de 11 de julho de 1989. Dispõe sobre a pesquisa, a experimentação, a produção, Brasília, DF, jul 1989, http://www. planalto. gov. br/ ccivil 03/ leis /L7802.htm. Acessado: junho 2017.

${ }^{47}$ Brasil. Decreto 4.074 de 4 de janeiro de 2002. Regulamenta a Lei no 7.802, de 11 de julho de 1989, que dispõe sobre a pesquisa, Brasília, DF, jan 2002, http://www. planalto. gov.br / ccivil 03/decreto/2002/D4074.htm\#art98. Acessado: junho 2017.

${ }_{48}$ Brasil. Decreto 5.981 de 6 de dezembro de 2006. Dá nova redação e inclui dispositivos ao Decreto no 4.074, Brasília, DF, dez 2006, http://www.planalto.gov.br/ccivil 03/ ato2004-2006/ 2006/ decreto/ d5981 .htm Acessado: junho 2017.

49 Tanny Oliveira Lima Bohner; Luiz Ernani Bonesso Araújo and Toshio Nishjima. O impacto ambiental do uso de agrotóxicos no meio ambiente e na saúde de trabalhadores rurais. Revista Eletrônica do Curso de Direito, Santa Maria, v. 8, (2013): 329-341, https://periodicos.ufsm.br/revistadireito / article/view/8280 Acessado: agosto 2017.
} 
Como explicado por Assis e Romeiro ${ }^{50}$ até a Segunda Revolução Agrícola, as tecnologias de cultivo respeitavam o meio ambiente, superando as limitações ecológicas impostas à atividade agrícola, através do entendimento do funcionamento da natureza. Com o avanço da química agrícola surgiu a agricultura moderna deixando-se de considerar a relevância das leis da natureza para a atividade agrícola, a ideia era que o caráter ambientalmente agressivo desta nova forma de agricultura poderia ser moderado com algumas práticas conservacionistas. A agroecologia é uma ciência que surge então como forma de estabelecer uma base teórica para uma produção agrícola que respeite as leis da natureza, procurando entender o funcionamento do agroecossistema e preservar e ampliar sua biodiversidade, auto regulação e sustentabilidade.

A agricultura orgânica difere da agroecologia quando se apresenta como uma prática agrícola voltada para o mercado de uma forma abrangente, em que agricultor e consumidor deixam de ter um contato próximo, estabelecendo uma ruptura entre o produto em si e a forma como este é produzido. A motivação para o consumo de produtos da agricultura orgânica é função, basicamente, da possibilidade de benefícios à saúde inerentes ao produto em si, sendo a questão fundamental não conter agrotóxicos, enquanto que, preocupações ambientais, mais associadas à forma de produção, são apontadas como motivação secundária para o consumo.

Contemporaneamente, assim, surge o desafio imediato de proteger a saúde dos consumidores e trabalhadores rurais diante da dimensão dos riscos para a saúde e o meio ambiente decorrentes da intensa exposição aos agrotóxicos. Nesse sentido é intenção desse trabalho demonstrar que as pesquisas por novos agroquímicos, com propriedades mais benéficas ao ser humano e ao meio ambiente, é um campo ativo no meio científico e pode contribuir até que se possa mostrar e convencer a população mundial de que é necessário repensar o modo de produção agrícola objetivando a preservação do meio ambiente e todos que dele dependem.

\footnotetext{
50 Renato Linhares de Assis and Ademar Ribeiro Romeiro. Agroecologia e Agricultura Orgânica: controvérsias e tendências, (Curitiba: Editora UFPR, 2002).
} 


\section{ESTRUTURA LEGAL DA AGROECOLOGIA NO BRASIL}

A agroecologia, enquanto tema relativamente recente, surge como campo cheio de possibilidades tendo fundamentação em diversas origens. Tal fato cria a necessidade de estabelecer bases sob aspectos legais e epistemológicos. Caporal e Costabeber $^{51}$ chegam a atestar isso quando afirmam que é notório para o desenvolvimento da agroecologia, enquanto alternativa à crise no modelo produtivista atual, sua regulamentação e organização estrutural.

Refletindo sobre o mencionado, Assis ${ }^{52}$ afirma que a evolução da agroecologia só se dará por intermédio da ação conjunta entre a comunidade acadêmica, o poder público e o mercado consumidor em seus diversos níveis de atividade. Isso com o objetivo de que haja a possibilidade de reagir aos problemas ambientais provocados pela agricultura convencional.

No Brasil, especificadamente, os aspectos legais estabelecidos para a agroecologia são vinculados a programas de desenvolvimento rural com a temática de inclusão social e manejo sustentável do solo, água e demais recursos, desenvolvidos nos anos de 1980 e 1990, como políticas públicas ambientais. Segundo Bianchini e Medaets $^{53}$, a Agroecologia começa a ser observada e analisada sob o ponto de vista legal com a substituição do termo "agricultura alternativa" por "agricultura agroecológica", isso quando há a formação de consórcios, redes e grupos voltados ao desenvolvimento e fundamentação da agroecologia em nível continental.

Legalmente, falando de leis escritas e com alguma repercussão em âmbito nacional, fazendo uma linha do tempo a fim de contextualizar o que se tem hoje, é possível identificar o Código Florestal pelo Decreto $23.793 / 1934{ }^{54}$, o Código de Águas pelo Decreto $24.643 / 1934^{55}$, o Estatuto da Terra pela Lei $4.504 / 1964^{56}$, o Novo Código

\footnotetext{
${ }^{51}$ Francisco Roberto Caporal and José Antônio Costabeber. "Agroecologia: alguns conceitos e princípios"

${ }^{52}$ Rento Linhares de Assis. "Agroecologia: Visão Histórica e Perspectivas no Brasil”. In Aquino, A. M. de; Assis, R. L. de. (Ed.). Agroecologia: princípios e técnicas para uma agricultura orgânica sustentável, p. 174-184.

${ }^{53}$ Valter Bianchin and Jean Pierre Passos Medaets. "Da revolução verde à agroecologia: Plano Brasil Agroecológico".

${ }^{54}$ Brasil. Decreto 23.793 de 23 de janeiro de 1934. Código Florestal, Rio de Janeiro, jan. 1934a, https://www. planalto. gov.br/ccivil 03/decreto/1930-1949/D23793.htm Acessado: junho 2017.

${ }^{55}$ Brasil. Decreto 24.643 de 10 de janeiro de 1934. Código das Águas, Rio de Janeiro, jan. 1934b, https:// www. planalto. gov. br/ c civil 03/decreto/d24643.htm. Acessado: junho 2017.

${ }^{56}$ Brasil. Lei 4.504 de 30 de novembro de 1964. Estatuto da Terra, Brasília, nov. 1964, http://www. planalto. gov. br/ccivil 03/leis/L4504.htm. Acessado: junho 2017.
} 
Florestal pela Lei 4.771/1965 ${ }^{57}$, a Proteção da Vegetação Nativa pela Lei 12.651/2012 ${ }^{58}$, o Sistema de Cadastramento Ambiental Rural pelo Decreto 7.830/2012 ${ }^{59}$ e, as Normas Gerais Complementares aos Programas de Regularização Ambiental dos Estados e do Distrito Federal pelo Decreto $8.235 / 2014^{60}$. Esses, cada um com seus objetivos e especificidades, alicerçaram a agroecologia pois, através dos mesmos foram estabelecidas novas regras sobre o uso dos solos, água e demais recursos, pendenciando sempre para uma vertente mais sustentável e, menos agressiva ao meio ambiente.

Posteriormente, com intuito de desenvolver a agricultura familiar foram estabelecidos pelo legislativo a Lei da Agricultura Familiar pela Lei $11.326 / 2006^{61}$ e a Política Nacional de Assistência Técnica e Extensão Rural - PNATER - pela Lei $12.188 / 2010^{62}$.Isso, além da Lei 11.947/2009 ${ }^{63}$ do Programa de Alimentação Escolar (PNAE) que garantia a inclusão da agricultura familiar na merenda escolar dos alunos de toda a educação básica matriculados na rede pública de ensino, essa inclusão deveria ser de, pelo menos, 30\%. No entanto, quanto a última lei mencionada, no início do processo de adequação, poucas escolas conseguiram que $30 \%$ da merenda distribuída a seus alunos fosse oriunda da agricultura familiar, dentre diversos fatores, por causa da falta de oferta desses produtos. Mas, é notório o impulso que a agricultura familiar ganhou com esse incentivo. Nesse âmbito, também houve o Programa de Aquisição de Alimentos - $\mathrm{PPA}^{64}$, que foi uma estratégia do Governo Federal a fim de mitigar a fome e a pobreza no país, de forma a fortalecer a agricultura

\footnotetext{
57 Brasil. Lei 4.771 de 15 de setembro de 1965. Novo Código Florestal, Brasília, set. 1965, http://www2. camara. leg.br/legin/fed/lei/1960-1969/lei-4771-15-setembro-196 5-369026-publicacaooriginal-1-pl.html. Acessado: junho 2017.

58 Brasil. Lei 12.651 de 25 de maio de 2012. Proteção da Vegetação Nativa, Brasília, mai. 2012a, http://www. planalto.gov.br/ccivil 03/ ato2011-2014/2012/lei//12 651 .htm. Acessado: junho 2017.

${ }^{59}$ Brasil. Decreto 7.830 de 17 de outubro de 2012. Sistema de Cadastramento Ambiental Rural, Brasília, out. 2012c, http://www.planalto.gov.br/ccivil 03/ ato2011-2 014/2012/decreto/D7830.htm Acessado: junho 2017.

${ }^{60}$ Brasil. Decreto 8.235 de 5 de maio de 2014. Normas Gerais Complementares aos Programas de Regularização Ambiental dos Estados e do Distrito Federal, Brasília, mai. 2014, http://www. planalto. gov.br/ ccivil 03/ Ato20112014/2014 /Decreto / D 8235 . h tm. Acessado: junho 2017.

61 Brasil. Lei 11.326 de 24 de julho de 2006. Lei da Agricultura Familiar, Brasília, jul. 2006b, http://www. planalto.gov.br/ccivil 03/ ato2004-2006/2006/lei/ 111326. htm. Acessado: junho 2017.

${ }^{62}$ Brasil. Lei 12.188 de 11 de janeiro de 2010. Política Nacional de Assistência Técnica e Extensão Rural (PNATER), Brasília, jan. 2010, http://www.google. com.br /url?sa= t\&rct= i\&q= \&esrc =s\&source =web\&cd= 1\&ved=0ahUKE wj69af2bn XAhVJm JAKH $\quad$ ce3BMcQFggnMAA\&url= $\quad$ http\%3A\%2F\%2Fportal. $\quad$ mda.gov.br\% 2Fo\%2F6421940\&usg=AOvVaw2Whr5nbrW09w5 nu5frUF2. Acessado: junho 2017.

63 Brasil. Lei 11.947 de 16 de junho 2009. Programa de Alimentação Escolar (PNAE), Brasília, jun. 2009a, http://www.planalto.gov.br/ccivil 03/ ato2007-2 010 / 2 009/lei/ I1 19 47.htm Acessado: junho 2017.

${ }^{64}$ Brasil. Programa de Aquisição de Alimentos (PPA), Brasília, 2003a, http://www.mda.gov.br/ sitemda/ secretaria/ safpaa/sobre-o-programa. Acessado: junho 2017.
} 
familiar. Para tanto, foram utilizadas formas de comercialização adquirindo produtos diretamente da agricultura familiar, agregando valor à produção.

Em 2003 a Lei ${ }^{\circ} 10.831^{65}$ determinou que a regulamentação das atividades de Agroecologia no Brasil são competência do Ministério da Agricultura, Pecuária e Abastecimento (MAPA). Esse último se estabeleceu no setor de Coordenação de Agroecologia e Produção Orgânica (COAGRE), onde há o desenvolvimento, a coordenação e execução de ações, inclusive de normatização, relacionado ao tema no Brasil.

Vinculados ao COAGRE, diversos marcos legais complementam a temática. Como exemplo se pode citar a Lei de Produção Orgânica, que estabelece padrões de produção e comercialização. Além do Decreto $n^{\circ} 6.323$ de dezembro de $2007^{66}$,que regulamenta essa lei promovendo um grande avanço sob o ponto de vista dos mecanismos de controle necessários para assegurar ao consumidor a qualidade do produto orgânico. Esse último também é capaz de prever mecanismos de controle para garantia da qualidade orgânica, o que tem dado destaque ao Brasil, no cenário internacional, ao reconhecer a importância dos sistemas de controle participativo e social, além da certificação por auditoria externa. Como mecanismos de controle, o Decreto $\mathrm{n}^{0} 6.913$ de julho de $2009^{67}$ altera a regulamentação da Lei de Agrotóxicos, que estabelece os procedimentos para o registro dos produtos fitossanitários com uso aprovado na agricultura orgânica. Determina ainda uma fonte de produtos aplicáveis à processos agroecológicos e orgânicos.

A introdução de regras mais claras e efetivas através da regulamentação brasileira de produção orgânica promoveu o fortalecimento e impulsionou o setor sustentável, inclusive agroecológico, pois estabeleceu processos e padrões para os produtos por meio do Sistema Brasileiro de Avaliação de Conformidade Orgânica. A legislação de orgânicos reconhece mecanismos de garantia de qualidade estabelecendo procedimentos que definem técnicas legalmente reconhecidas. Tal

\footnotetext{
${ }^{65}$ Brasil. Lei 10.831 de 23 de setembro de 2003. Agricultura Orgânica, Brasília, set. 2003b, http://www. planalto. gov.br/ccivil 03/leis/2003/L10.831.htm. Acessado: junho 2017.

66 Brasil. Decreto 6.323 de 27 de dezembro de 2007. Agricultura Orgânica, Brasília, dez. 2007, http://www. planalto.gov.br/ccivil 03/ ato2007-2010/2007/decreto / d6323 h t m. Acessado: junho 2017.

Brasil. Decreto 6.913 de 23 de julho de 2009. Lei de Agrotóxicos, Brasília, jul. 2009b, http://www. planalto. gov.br/ccivil 03/ ato2007-2010/2009/decreto/d6913.htm. Acessado: junho 2017.
} 
padronização permite que a produção de origem agroflorestal se estabeleça em nichos de mercado outrora vazios nos cenários nacionais e internacionais.

Segundo Bianchini e Medaets $^{68}$,mesmo estabelecidos os protagonismos a nível de regulamentação das atividades de Agroecologia no Brasil como competência do MAPA, a amplitude de cenários de atuação do campo permite que sejam estabelecidas ações de outras frentes no tema. O Ministério do Desenvolvimento Agrário (MDA) e o Instituto Nacional de Colonização e Reforma Agrária (INCRA) vem integrando novos conceitos e diretrizes na Assistência Técnica e Extensão Rural (ATER). Há nesses órgãos o direcionamento do foco reflexivo e de ação para a agricultura familiar e a promoção do desenvolvimento rural sustentável, como estratégia baseada em um projeto de desenvolvimento regional e local, para o rural. O objetivo é a integração de organizações públicas e privadas na qualificação de agentes da ATER nos princípios da agroecologia. Nesse âmbito, a Política Nacional de Assistência Técnica e Extensão Rural (PNATER) definiu que fossem incorporados princípios, diretrizes e objetivos à agroecologia. Foram lançadas várias chamadas públicas pela ATER para financiar a atividade de extensionistas que atuam com esse enfoque, além do estabelecimento de centros de formação e capacitação no tema.

Além disso, não se pode deixar de mencionar o Plano Nacional de Agroecologia e Produção Orgânica (PLANAPO) fundamentado pela Política Nacional de Agroecologia e Produção Orgânica (PNAPO) a partir do decreto 7.794/2012 ${ }^{69}$. A PNAPO teve como objetivo aumentar as ações para efetivação do desenvolvimento rural sustentável. Nesse patamar, o PLANAPO objetivou incentivar a iniciativa pública e privada às práticas agroecológicas, incluir a ideologia agroecológica nos planejamentos de políticas públicas e, articular ações de transição agroecológica e produção orgânica.

A partir de todos esses dados, evidencia-se que o estabelecimento de bases legais promoveu o desenvolvimento da agroecologia enquanto ciência. Isso através da padronização de ações como a abertura do mercado, financiamento, pesquisas,

\footnotetext{
${ }^{68}$ Valter Bianchini and Jean Pierre Passos Medaets. Da revolução verde à agroecologia: Plano Brasil Agroecológico.

69 Brasil. Decreto 7.794 de 20 de agosto de 2012. Política Nacional de Agroecologia e Produção Orgânica, Brasília, 2012b, http://www.planalto. gov.br/ccivil 03/ ato2011-2 0 14/2012/decreto/d7794 Acessado: junho 2017.
} 
profissionais e núcleos interessados para a evolução do tema. Cada lei ou decreto citados trouxeram mudanças efetivas ressaltando a amplitude e efetividade das atividades desenvolvidas.

\section{CONSIDERAÇÕES FINAIS:}

Com base em tudo o que foi dito, salienta-se que o modo de produção capitalista da contemporaneidade tem promovido o uso indiscriminado do solo e seus recursos. A agroecologia surge nesse contexto como uma forma alternativa, que procura ser sustentável, de se melhor utilizar o solo mitigando sua degradação. Nessa, procura-se valorizar, dentre outras coisas, o "conhecimento de causa" do pequeno agricultor que vive da terra que cultiva.

É analisado que, em meio a uma era movida pela mecanização e novas tecnologias, a agroecologia pode ser interpretada enquanto um retrocesso e ser repelida. Isso principalmente quanto ao uso de agrotóxicos que visa maior produção em menos tempo, o que em teoria poderia "acabar com a fome no mundo". No entanto, é percebido também que, como não é possível se inserir a agroecologia no processo de avanço agropecuário em andamento só a partir de uma ideologia preservacionista, a miscigenação de correntes e ideologias pode ser uma alternativa. Além de não se perder a perspectiva de dar voz a experiência do pequeno agricultor que sobrevive da terra.

Há muito o que se fazer em termos de legislação ainda no Brasil quando se fala em preservação. Como mencionado, já existem leis de regulamentação, no entanto, a falta de fiscalização e execução das punições fazem com que a impunidade seja um dos fatores que impulsionem o mau uso do solo e a degradação desenfreada do meio ambiente.

A agroecologia enquanto disciplina, enquanto ciência é um campo relativamente novo na literatura acadêmica, vem ganhando espaço gradativamente, e merece mais destaque. No entanto, salienta-se que no cenário de desenvolvimento capitalista atual, sua abordagem pragmática e incisiva não terá êxito se tiver que concorrer com o lucro proporcionado pelo avanço da agricultura convencional. Para 
que ela seja ouvida, analisada e praticada será necessária uma miscigenação de conceitos, filosofias e práticas. Provavelmente isso não seja o ideal para o planeta, contudo, é o mais possível no momento e, com certeza é um começo.

AGRADECIMENTOS: Os autores agradecem o apoio recebido para a pesquisa, a saber, Bolsa fomentada pela Universidade Estadual de Goiás (UEG) e Bolsa da Fundação de Amparo à Pesquisa do Estado de Goiás (FAPEG).

\section{FONTES DOCUMENTAIS}

Brasil. Decreto 23.793 de 23 de janeiro de 1934. Código Florestal, Rio de Janeiro, jan. 1934a. Disponivel em https://www. planalto. gov.br/ccivil_03/decreto/19301949/D23793.htm. Acessado: junho 2017.

Governo do Brasil Decreto 24.643 de 10 de janeiro de 1934. Código das Águas, Rio de Janeiro, jan. 1934b. Disponível em https://www.planalto. gov. br/ c civil_03/decreto/d24643.htm. Acessado: junho 2017.

Governo do Brasil Decreto 4.074 de 4 de janeiro de 2002. Regulamenta a Lei no 7.802, de 11 de julho de 1989, que dispõe sobre a pesquisa, Brasília, DF, jan 2002. Disponível em http://www. planalto. gov.br / ccivil 03/decreto/2002/D4074.htm\#art98. Acessado: junho 2017.

Governo do Brasil Decreto 5.981 de 6 de dezembro de 2006. Dá nova redação e inclui dispositivos ao Decreto no 4.074, Brasília, DF, dez 2006a . Disponível em http:// www. pla na lto. gov. br /cc ivil_03/_ ato 2004-2006/2006/decreto/d5981.htm. Acessado: junho 2017.

Governo do Brasil Decreto 6.323 de 27 de dezembro de 2007. Agricultura Orgânica, Brasília, dez. 2007. Disponível em http://www.planalto.gov.br/ccivil 03/ ato20072010/2007/decreto / d6323 h t m. Acessado: junho 2017.

Governo do Brasil Decreto 6.913 de 23 de julho de 2009. Lei de Agrotóxicos, Brasília, jul. 2009b. Disponível em http://www.planalto.gov.br/ccivil_03/_ato20072010/2009/decreto/d6913.htm. Acessado: junho 2017.

Governo do Brasil Decreto 7.794 de 20 de agosto de 2012. Política Nacional de Agroecologia e Produção Orgânica, Brasília, 2012b. Disponível em http://www.planalto. gov.br /ccivil_03/_ato2011-2 0 14/2012/decreto/d7794.htm Acessado: junho 2017.

Governo do Brasil Decreto 7.830 de 17 de outubro de 2012. Sistema de Cadastramento Ambiental Rural, Brasília, out. 2012c. Disponível em 
http://www.planalto.gov.br/ccivil 03/ ato2011-2 014/2012/ decreto/D7830.htm . Acessado: junho 2017.

Governo do Brasil Decreto 8.235 de 5 de maio de 2014. Normas Gerais Complementares aos Programas de Regularização Ambiental dos Estados e do Distrito Federal, Brasília, mai. 2014.2 Disponível emhttp://www.planalto.gov.br/ccivil_03/_Ato2011-2014/2014 /Decreto / D 8235. $\underline{\mathrm{h} \mathrm{tm}}$. Acessado: junho 2017.

Governo do Brasil Lei 10.831 de 23 de setembro de 2003. Agricultura Orgânica, Brasília, set. 2003b. Disponível em http://www.planalto.gov.br/ccivil_03/leis/2003/L10.831.htm. Acessado: junho 2017.

Governo do Brasil Lei 11.326 de 24 de julho de 2006. Lei da Agricultura Familiar, Brasília, jul. 2006b. Disponível em http://www.planalto.gov.br/ccivil 03/ato20042006/2006/lei/111326. Htm. Acessado: junho 2017.

Governo do Brasil Lei 11.947 de 16 de junho 2009. Programa de Alimentação Escolar (PNAE), Brasília, jun. 2009a ${ }^{a}$ Disponível em http://www.planalto.gov.br/ccivil 03/ato2007-2 $010 / 2$ 009/lei/ 1119 47.htm . Acessado: junho 2017.

Governo do Brasil Lei 12.188 de 11 de janeiro de 2010. Política Nacional de Assistência Técnica e Extensão Rural (PNATER), Brasília, jan. 2010. Disponível em http://www.google. com.br /url?sa $=\quad t \& r c t=\quad j \& q=\& e s r c=s \& s o u r c e=w e b \& c d=$ 1\&ved=0ahUKE wj69af2bn $\quad$ XAhVJm $\quad$ JÁ $\quad$ KH $\quad$ ce3BMcQF ggnMAA\&url=http\%3A\%2F\%2Fportal.mda.gov.br\% $\quad$ 2Fo\%2F6421940 \&usg =AOvVaw2Whr5nbrW09w5_nu5frUF2. Acessado: junho 2017.

Governo do Brasil Lei 12.651 de 25 de maio de 2012. Proteção da Vegetação Nativa, Brasília, mai. 2012a. Disponível em http://www.planalto.gov.br/ccivil 03/ato20112014/2012/lei/112 651 .htm. Acessado: junho 2017.

Governo do Brasil Lei 4.504 de 30 de novembro de 1964. Estatuto da Terra, Brasília, nov. 1964. Disponível em http://www.planalto.gov.br/ccivil_03/leis/L4504.htm. Acessado: junho 2017.

Governo do Brasil Lei 4.771 de 15 de setembro de 1965. Novo Código Florestal, Brasília, set. 1965. Disponível em http:// www2.camara.leg.br/legin/fed/lei/1960-1969/lei4771-15-setembro-196 5-369026-publicacao original-1-pl.html. Acessado: junho 2017.

Governo do Brasil Lei $\mathrm{N}^{\circ} 7.802$ de 11 de julho de 1989. Dispõe sobre a pesquisa, a experimentação, a produção, Brasília,DF, jul 1989. Disponível em http://www. planalto. gov. br/ccivil_03/leis /L7802.htm. Acessado: junho 2017.

Governo do Brasil Programa de Aquisição de Alimentos (PPA), Brasília, 2003a. Disponível em http://www.mda.gov.br/ sitemda/secretaria/saf-paa/sobre-oprograma. Acessado: junho 2017. 


\section{REFERÊNCIAS BIBLIOGRÁFICAS}

Alexander Ritter, Simone Elenice Castelan and Cassiana Grigoletto. Agroecologia, desenvolvimento sustentável e educação ambienta. Ministério da Educação Coordenação de Aperfeiçoamento de Pessoal de Nivel Superior Programa Institucional de Bolsa de Iniciação à Docência, Sub-projeto: Agroecologia e desenvolvimento rural sustentável: Rio Grande do Sul, (2003): 2, http://www.sertao.ifrs.edu.br/site/midias Larquivos/2013311105741464 artigo_agroecologia,__esenvolvimento_ sustentavel e educacao ambiental.pdf

Ana Maria Primavesi. Agroecologia e manejo do solo. Agriculturas 5,3 (Setembro 2008), http:// aspta. org. br/wp-content/uploads/2014/10/Artigo-1-Agroecologiae-manejo-do-solo.pdf

Ana Ruth Lima Arcanjo. "Estudo da aplicabilidade dos testes imunocromatográficos como diagnóstico da malária na atenção básica de saúde no município de Manaus". (Dissertação de Mestrado, Universidade Estadual do Amazonas, 2004), http: //www. pos. uea. edu .br/data/area/dissertacao/download/2-1.pdf.

Claudio D'Amato, João P. M. Torres and Malm Olaf. DDT (Dicloro Difenil Tricloroetano): Toxicidade e Contaminação Ambiental - Uma Revisão. Química Nova 25,6 (2002): 995-1002.

Cristiane Francis dos Santos Tonezer and Anelise Graciele Rambo. Agroecologia e agricultura familiar: Um caminho para a soberania alimentar. In $47^{\circ}$ Congresso Sociedade Brasileira de Economia, Administração e Sociologia Rural, jul./2009: 8, http://www2. ufersa. edu. br/portal/view/ up loads/setores/241/Agroecologia \% 20 e $\% 2$ 0Agricultura \%20 Familiar\%20-\%20 Um\%20caminho \%20para\%20a\% 20soberania\% 20 Alimentar.pdf

Elaine de Azevedo and Maria Cecília Focesi Pelicione. Promoção da saúde, sustentabilidade e agroecologia: uma discussão intersetorial. Saúde Soc., 20,3 (2011), 720 http://www.scielo.br /scielo . php? script=sci_arttext\&pid=S0104$\underline{12902011000300016}$

Erney Plessmann Camargo. Malária, maleita, paludismo. Revista Ciência e Cultura. 55,1 (Jan.-Mar. 2003), http://cienciaecultura.bvs.br/ scielo. php? pid=s0009-67 25200300 $\underline{0100021 \& \text { script }=\text { sci } \_ \text {arttext. }}$.

Francisco Roberto Caporal and José Antônio Costabeber. Agroecologia: alguns conceitos e princípios. (Brasília: MDA/SAF/DATER-IICA, 2004: 06), http://www.fca.unesp. br/Home /Extensao / G rupoTimbo/ AgroecologiaConceitoseprincipios.pdf

Agroecologia e Desenvolvimento Rural Sustentável: perspectivas para uma Nova Extensão Rural. Agroecologia e Desenvolvimento Rural Sustentável. 1,1 (jan.-mar. 2000): 
32 http: // www . projetovidanocampo.com.br /agroecologia/ agroecologia e desesenvolv imento .pdf

Instituto Brasileiro do Meio Ambiente e dos Recursos Naturais - IBAMA. "Químicos e Biológicos: Agrotóxicos" (2018). Disponível em http://www.ibama.gov.br/agrotoxicos. Acessado: Maio 2018

José Prado Alves Filho. Uso de agrotóxicos no Brasil: Controle social e interesses corporativos, Controle social e interesses corporativos. (São Paulo: Annablume: Fapesp, 2002), 23.

Letícia Fátima de Azevedo and Tatiane Almeida Netto. Agroecologia: o caminho para o desenvolvimento rural sustentável no processo de extensão rural. In Revista Eletrônica em Gestão, Educação e Tecnologia Ambiental, 19,3 (set.-dez. 2015), 639-645, https://periodicos. ufsm.br/reget/article / view /17031

Mara Elisa Fortes Braibante and Aline Zappe Janessa. A Química Dos Agrotóxicos. Química Nova Na Escola 34,1 (2012): 10-15.

Maristela Simões do Carmo. Agroecologia: Novos caminhos para a agricultura familiar. Revista Tecnologia \& Inovação Agropecuária, 1 (2008), 28-39, http://www.apta.sp.gov.b r/Publicacoes/ $\quad$ T\&IA2/ $\quad T \quad$ \& Av1n2/Artigo_Agroecologia_Novos_Caminhos_3.pdf

Miguel Altieri. Agroecologia: bases científicas para uma agricultura sustentável (São Paulo: Expressão Popular, 2012), 202.

Pedro Tauil, et al. A malária no Brasil. Caderno de Saúde Pública 1,1 (Jan.-Mar 1985) http://www.scielo.br/scielo.php?script=sci_ 131arttext \&pid = S0102-311X 1985000 100009

Raiza Tourinho and Graça Portela. Agroecologia é alternativa para cultivo agrícola mais sustentável (Rio de Janeiro: FIOCRUZ, 2016), https://portal.fiocruz.br/pt-br/co ntent/ agroe co logia-e-alternativa-para-cultivo-agricola-mais-sustentavel.

Renato Linhares de Assis and Ademar Ribeiro Romeiro. Agroecologia e Agricultura Orgânica: controvérsias e tendências, (Curitiba: Editora UFPR, 2002).

Renato Linhares de Assis. Agroecologia: Visão Histórica e Perspectivas no Brasil. In Aquino, A. M. de; Assis, R. L. de. (Ed.). Agroecologia: princípios e técnicas para uma agricultura orgânica sustentável. (Brasília: Embrapa Informação Tecnológica; Seropédica: Embrapa Agrobiologia, 2005), 176 https://www. agencia. cnptia. embrapa.br/recursos/AgrobCap7ID-MWV9UkYXu0

Tanny Oliveira Lima Bohner; Luiz Ernani Bonesso Araújo and Toshio Nishjima. O impacto ambiental do uso de agrotóxicos no meio ambiente e na saúde de trabalhadores rurais. Revista Eletrônica do Curso de Direito, Santa Maria, v. 8, (2013): 
329-34. Disponivel em https:// periodicos. ufsm. br/revistadireito / article/view/8280. Acessado: Agosto de 2017

Valdir Lamim-Guedes. Pegada ecológica: consumo de recursos naturais e meio ambiente. Educação Ambiental e Ação. 38 (dez.-fev./2011-2012), http://www.revistae.org/artigo.php? idartigo $=1168$

Valter Bianchini and Jean Pierre Passos Medaets. Da revolução verde à agroecologia: Plano Brasil Agroecológico.http://www.mda.gov.br /portalmda /sites /default/files/user_ arq uivos _ 195 /Brasil\%20Agroecol\%C3\%B3gico\%20271113\%20 Artigo \% 20Bianchini \%20e\%20 Jean \% 20Pierre.pdf 


\title{
Agroecology yesterday, today and tomorrow in Tupiniquins Lands: Concept, context and perspectives
}

\begin{abstract}
Agroecology is based on the idea that the development of sustainable agriculture is possible. Therefore, the present work aims to analyze agroecology as an alternative to mitigate the environmental degradation that conventional agriculture has caused. This is a bibliographical research, in which were consulted books, scientific articles and laws that corroborated with the information and analyzes presented here. The work is structured as follows: 1. The concept of agroecology is worked according to authors of the academic literature; 2. A historical contextualization of the emergence of agroecology in the world and, later, in Brazil; 3. The situation of agroecology is currently being considered, with an emphasis on the problems it has faced; 4 . The insertion of agrochemicals in conventional agriculture is analyzed; 5. The legal structuring of agroecology in Brazil is presented. It was found that current agriculture has been structured by high dependence on chemical inputs, intensive mechanization and unsustainable use of natural resources, so it is necessary to have a dialogue of these practices with the actions of agroecology.
\end{abstract}

Keywords: Earth; Conventional agriculture; Ambiental degradation; Mechanization; Legislation.

Recibido: $15 / 05 / 2018$

Aprobado: 15/08/2018 